\title{
Preparação e Condução de uma Aula Síncrona On-Line em um Curso a Distância de Formação de Professores
}

\author{
Sílvia Dotta1, Diego Marques', Edson Pimentel ${ }^{1}$. Juliana Braga1, Claudineia \\ Lizieri $^{2}$, Francyne Elias-Piera ${ }^{3}$, Nubia Caramello ${ }^{4}$ \\ ${ }^{1}$ Universidade Federal do ABC - Centro de Matemática, Computação e Cognição \\ Rua Abolição, s/n, bloco L, Lab. 119 - CEP 09210-180, Santo André, SP - Brasil \\ ${ }^{2}$ Centro Universitário de Belo Horizonte-UniBH/APECS-Brasil Avenida Professor \\ Mário Werneck 1685 campus Buritis, Belo Horizonte, MG - Brasil \\ ${ }^{3}$ Korea Polar Research Institute - KOPRI - 26, Songdomirae-ro, Incheon - Korea \\ ${ }^{4}$ Secretária de Educação do Estado de Rondônia/ SEDUC/RO -Brasil \\ silvia.dotta, diego.marques, edson.pimentel, juliana.braga, @ufabc.edu.br; c.lizieri@gmail.com; \\ francyne.ep@kopri.re.kr; nubiacaramello@yahoo.com.br
}

\begin{abstract}
This paper reports the process of preparation and realization of the inaugural class of the distance course Antarctic or Antarctica? How to insert the polar sciences in the school curriculum of the elementary school, offered by a Brazilian public university. The presuppositions of dialogic learning guided the work for the offering of synchronous virtual classes organized by multidisciplinary teams. The class, elaborated according to the Intera methodology, was transmitted by Youtube and connected to students distributed in Portugal and 14 Brazilian states. In the end, it is considered essential to use multimodal and multimedia web conferencing systems with numerous possibilities for interaction.
\end{abstract}

Resumo. Este trabalho reporta o processo de preparação e realização da aula inaugural do curso a distância Antártica ou Antártida? Como inserir as ciências polares no currículo escolar do ensino básico, oferecido por uma universidade pública brasileira. $O$ trabalho foi norteado pelos pressupostos da aprendizagem dialógica para a oferta de aulas virtuais síncronas organizadas por equipes multidisciplinares. A aula elaborada de acordo com a metodologia Intera, foi transmitida pelo Youbube e conectou cursistas distribuídos em Portugal e 14 estados brasileiros. Ao final, considerou-se essencial o uso de sistemas de webconferência multimodais e multimídias com inúmeras possibilidades de interação. 
VII Congresso Brasileiro de Informática na Educação (CBIE 2018)

Anais do XXIV Workshop de Informática na Escola (WIE 2018)

\section{Introdução}

Uma das dificuldades encontradas na prática da Educação a Distância (EaD) é a necessária sensação de presença, de pertencimento, que os cursistas almejam ter. $\mathrm{O}$ silêncio virtual ou a sensação de não pertencimento podem ser causadores, dentre outros, dos altos índices de evasão. Uma forma de ampliar a socialização entre os estudantes a distância é a promoção de encontros síncronos (presenciais ou online). Entretanto, esse tipo de atividade fere uma qualidade básica da EaD: a flexibilidade de tempo e espaço para a participação das aulas (Dotta, 2014), isto é, se uma das vantagens da EaD é essa flexibilidade, ao se proporem atividades síncronas, nem sempre será possível garantir a presença de todos os alunos.

O nível de fluência técnica dentre participantes de cursos a distância também é fator crucial para sua permanência nesses cursos. Maia e Meirelles (2005) identificaram haver relação direta entre o índice de evasão e as tecnologias utilizadas, sendo estas, uma das principais razões da evasão em EaD. Há ainda as razões pessoais de cada cursista para abandonar os cursos, mas essas por serem exógenas ao curso ou à instituição tornam-se difíceis, se não impossíveis, de serem gerenciadas na oferta dos cursos. As duas primeiras razões - sensação de pertencimento e fluência técnica - são problemas que podem ser confrontados no desenho do curso a distância. A inserção de encontros presenciais síncronos - físicos ou a distância - pode contribuir para a solução do problema.

Neste trabalho, apresentamos o processo de preparação e condução online de uma aula inaugural presencial em um curso de extensão a distância, oferecido por uma universidade pública brasileira a professores brasileiros e portugueses, intitulado Antártica ou Antártida? Como inserir as ciências polares no currículo do ensino básico. O curso, com 60 horas/aula a distância, oferece uma oportunidade para fortalecer o conhecimento de professores da educação básica sobre a importância da pesquisa Antártica e sobre a relevância desse continente para o Brasil e o Planeta, em uma perspectiva de construção de estratégias para inserir temas antárticos nas salas de aula dos ensinos fundamental e médio. Em posse do conhecimento polar os cursistas podem correlacioná-lo com o ambiente vivido, levando para a sala de aula uma temática que $a$ priori estaria desconectada da realidade do corpo discente e até mesmo docente.

O principal objetivo da aula inaugural foi estabelecer vínculos sociais entre os cursistas e a equipe multidisciplinar responsável pela condução do curso - mediadores pedagógicos e mediadores técnicos -, além de apresentar o curso e o ambiente virtual de aprendizagem, explicitando como estudar a distância, como interagir com o curso, colegas de turma e tutores, e como realizar e entregar as atividades propostas. A presença na aula era obrigatória para os residentes da região metropolitana de São Paulo, os quais participaram fisicamente, e ocorreu na sede da instituição, os demais cursistas se conectaram virtualmente.

Optamos por transmitir a aula utilizando o Youtube como sistema de webconferência, a fim de tentar estabelecer vínculos entre a equipe que ofereceu o curso e os cursistas. Na seção 2 Docência em aulas síncronas a distância, apresentamos a fundamentação teórica que norteia o trabalho. Na seção 3 Preparação e condução da aula inaugural, apresentamos a metodologia. Discutimos os resultados na seção 4, e tecemos nossas considerações finais na seção 5 . 
VII Congresso Brasileiro de Informática na Educação (CBIE 2018)

Anais do XXIV Workshop de Informática na Escola (WIE 2018)

\section{Docência em aulas síncronas a distância}

Um dos desafios enfrentados por docentes em Educação a Distância (EaD) é desenvolver estratégias eficazes para a condução do diálogo e para o engajamento dos estudantes nos processos de aprendizagem (Silva, 2000; Moore e Kearsley, 2013). Afora o necessário domínio técnico das ferramentas de comunicação, síncrona ou assíncrona, a escolha da linguagem apropriada, a postura a ser assumida pelo professor, as estratégias de interação, entre outros , são fatores cruciais para o processo de aprendizagem.

Em Tori (2017) entendemos que é possível que estudantes se mostrem presentes e envolvidos nas interações por meio da internet. Em alguns casos as interações a distância acabam potencializando a intimidade e empatia entre colegas que fisicamente não estabeleceriam uma comunicação, logo, as tecnologias interativas podem aproximar, com menor custo e maior eficiência. Hoje, sabe-se que as tecnologias de redução de distâncias já estão incorporadas em nosso cotidiano, buscando aumentar a sensação de proximidade percebida, minimizando substancialmente os efeitos da distância na aprendizagem.

Sistemas de webconferência multimodal e multimídia podem favorecer que sentimentos de empatia e interações pessoais sejam mais intensamente encorajados, pois oferecem múltiplas possibilidades de interação (Dotta, et al., 2012). A webconferência multimodal possui inúmeras ferramentas de comunicação em um mesmo ambiente, permitindo interações multidirecionais por voz, texto (chat) e vídeo. A webconferência multimídia possibilita o compartilhamento de arquivos, de aplicativos, de telas do computador e outros recursos. Além dessas características, esses sistemas possuem recursos comuns às salas de aula, como quadro branco e organização de grupos, ferramentas que auxiliam na condução de aulas e atividades colaborativas.

Diversos ambientes virtuais de aprendizagem propiciam uma comunicação multimodal rica em diversas modalidades como fala, gestos, texto, processamento de imagem, entretanto, grande parte deles é oferecida em versões pagas, o que dificulta sua adoção em instituições públicas de ensino. O YouTube, uma plataforma amplamente utilizada atualmente, é um ambiente que permite a transmissão gratuita de vídeos. Realizar uma webconferência síncrona (Dotta, 2014; Dotta et al. 2012), justifica-se pela necessidade de transformar cursos centrados em conteúdo para cursos centrados no diálogo. A presença síncrona de professores e alunos favorece a sensação de pertencimento ao grupo, promovendo o engajamento do aluno que é importante nos cursos a distância.

De acordo com Dotta et al. (2012), as preocupações de se praticar um diálogo que tem como consequência gerar o engajamento e pertencimento ao grupo, tem sido foco de pesquisa desde os primeiros estudos sobre a comunicação mediada por computador no contexto da Educação. Em suas pesquisas, os autores apontam que a educação a distância pode ser muito mais social do que parece, evitando diálogos polarizados e oferecendo oportunidades de comunicação para os diversos tipos de perfis de estudantes.

Os problemas de comunicação em uma aula a distância podem ser minimizados ou potencializados devido a aspectos técnicos. Tomemos como exemplo o uso da webconferência para a condução de aulas síncronas. Em estudos sobre a webconferência multimodal e multimídia, Dotta et al. (2012) já apresentaram preocupações em relação à instabilidade e velocidade de conexão com a internet, dificuldades de configurações de 
VII Congresso Brasileiro de Informática na Educação (CBIE 2018)

Anais do XXIV Workshop de Informática na Escola (WIE 2018)

áudio, vídeo ou outras, isto é, problemas técnicos incomuns à sala de aula presencial. Esse tipo de comunicação envolve o domínio de inúmeras funcionalidades do ambiente computacional, fluência no uso simultâneo de algumas ferramentas e alta capacidade para a gestão da comunicação entre os participantes - desafios pouco documentados e que ainda estão presentes na condução de uma comunicação dialógica e multimodal em aulas virtuais síncronas.

A condução e transmissão de uma aula síncrona, que atinja os objetivos de aprendizagem, exige a integração de inúmeras competências, observadas em profissionais como o especialista em conteúdo, educador, técnico de web, programador, designer instrucional, designer gráfico, roteirista, tutor . Em uma aula síncrona a distância por webconferência o professor assume vários papéis: papel pedagógico, papel social, papel gerencial e papel técnico (Dotta et al., 2012).

Segundo Dotta et al. (2012), no papel pedagógico o docente tem como principal função ser um mediador da aprendizagem, definir os objetivos educacionais a serem alcançados, os conteúdos abordados e as estratégias que serão adotadas com os alunos. $\mathrm{O}$ papel social é relacionado à responsabilidade que o docente tem de criar condições para que se estabeleça um clima amigável entre os estudantes e que estes interajam entre si. $\mathrm{O}$ professor deve ajudar os alunos a desenvolverem a capacidade de trabalhar em grupo. $\mathrm{O}$ papel gerencial é relacionado à administração, por parte do docente, de todas as situações e atividades do curso em relação ao tempo programado. O papel técnico é levar os estudantes a sentirem-se confortáveis em relação à tecnologia empregada, especialmente quanto à utilização do software. O objetivo do docente deve ser o de fazer com que a tecnologia seja o mais transparente (imperceptível) possível, de modo que os estudantes possam se concentrar nos conteúdos abordados e que o aparato tecnológico seja apenas um meio através do qual todos estarão conectados (Dotta et al., 2012).

A realização de todos esses papéis torna a função docente difícil de ser realizada individualmente, surgindo, portanto, a necessidade de se considerar o professor coletivo (Belloni, 1999), isto é, uma equipe com várias pessoas responsáveis por fazer cumprir todos os papéis de um professor em sala de aula, invariavelmente exercidos por uma equipe multidisciplinar. A condução de uma aula por webconferência deve ser realizada por uma equipe multidisciplinar, cujos papéis são divididos para não ocorrer prejuízos na condução da aula, garantindo a manutenção da interação entre docente e alunos e a invisibilidade dos aparatos técnicos como apontado por Dotta et al. (2012).

Considerando o exposto, neste trabalho estudamos a preparação técnica e a condução de uma aula transmitida por webconferência síncrona para alunos de um curso de extensão a distância, conforme apresentamos na próxima sessão.

\section{Preparação e condução da aula inaugural}

O curso de extensão a distância Antártica ou Antártida? Como inserir as ciências polares no currículo escolar do ensino básico, de 60 horas/aula, foi ofertado por uma universidade pública brasileira para professores da educação básica brasileira e portuguesa. A quarta edição do curso aqui estudada aconteceu nos meses de setembro a dezembro de 2017, tendo a primeira aula presencial (física ou a distância) e todas as demais ocorreram a distância mediadas pelo Ambiente Virtual de Aprendizagem (AVA) Moodle. 
VII Congresso Brasileiro de Informática na Educação (CBIE 2018)

Anais do XXIV Workshop de Informática na Escola (WIE 2018)

A participação da aula inaugural era uma exigência da coordenação do curso que tinha por objetivo minimizar os problemas levantados na introdução deste trabalho, e nessa aula os cursistas seriam apresentados aos temas do curso e aprenderiam a utilizar os recursos técnicos do AVA e das ferramentas necessárias para a realização das atividades. Além disso, os cursistas das diversas regiões poderiam se encontrar, presencial ou virtualmente e conhecer a equipe que conduziria o curso.

A preparação e condução da aula inaugural por webconferência contou com uma equipe multidisciplinar formada por administrador da sala virtual, docente, mediadores pedagógicos (tutores), mediadores técnicos, designer e estudantes.

A preparação da aula foi estruturada de acordo com a metodologia Intera. (Braga, Dotta e Pimentel, 2015; Braga et al. 2012) e seguiu as seguintes etapas:

(i) Contextualização: foi analisada a conjuntura da aula inaugural. Buscamos informações acerca do público alvo, composto por professores da educação básica em exercício ou em formação das regiões do Brasil e de Portugal; quantidade prevista de espectadores simultâneos; conhecimento prévio destes em relação ao tema a fim de adequar a linguagem e organização de informações da aula. Analisamos também a necessidade de inclusão de mediadores pedagógicos distribuídos em diferentes canais (chat, Facebook, Moodle e Whatsapp), assim como a infraestrutura necessária para a transmissão síncrona (conexão com a internet, software de broadcast, câmeras, computadores, ).

(ii) Requisitos: foram coletados e analisados todos os elementos funcionais e pedagógicos necessários para a realização da aula inaugural. Verificamos a elaboração textual, apresentação de slides, artefatos digitais e audiovisuais como vídeos para exibir durante a aula, a interface de comunicação com os cursistas e assim por diante. Selecionamos também nesta etapa as referências conceituais para fundamentação da aula.

(iii) Arquitetura: a equipe definiu e organizou o tema, conteúdo programático, vídeos, roteiros da apresentação e pauta da aula.

(iv) Desenvolvimento: a aula foi desenvolvida por uma equipe multidisciplinar procurando atender a ideia de professor coletivo destacada na seção anterior. A docente e coordenadora do curso elaborou a aula. Foram definidos alguns polos de recepção da aula (Belo Horizonte, Natal e Rolim de Moura) no qual pesquisadores (conteudistas e multiplicadores) participantes da elaboração dos materiais didáticos e da oferta do curso receberam os cursistas da Região. Os pesquisadores, que não estavam fisicamente na transmissão, enviaram vídeos apresentando seus papéis no curso e se apresentando para a turma. Designers, produtores de vídeo e redatores se dedicaram para a construção dos textos, slides, gravação dos vídeos de apresentação e configuração da transição entre cenas do software de transmissão. Tutores técnicos e pedagógicos estabeleceram a recepção online dos cursistas, procurando mantê-los no ambiente da aula por meio da interação via chat. Este foi o momento da efetiva condução da aula inaugural.

(v) Testes: essa etapa permitiu antecipar os problemas técnicos da transmissão. $\mathrm{O}$ contexto de transmissão foi uma sala de aula com velocidade de conexão de internet e políticas de segurança da rede limitados pela universidade. No primeiro teste para verificar a compatibilidade do sistema de transmissão com as políticas de segurança, realizamos rotinas de teste via conexão de internet wi-fi e rede cabeada para assegurar que não existia bloqueio para o streaming. $\mathrm{O}$ segundo teste foi realizado com uma câmera 
VII Congresso Brasileiro de Informática na Educação (CBIE 2018)

Anais do XXIV Workshop de Informática na Escola (WIE 2018)

GoPro $^{1}$ conectada ao notebook pela rede wi-fi dedicada deste dispositivo, o sistema de conexão é nativo da câmera que gerou a interface de conexão com o notebook que estava conectado à internet via rede cabeada. $O$ áudio foi gerado através do microfone da câmera e headset quando realizada a transição de cenas pelo software de broadcast.

(vi) Disponibilização: A transmissão da aula foi realizada ao vivo pelo sistema de streaming do YouTube. Utilizamos o software livre e de código aberto Open Broadcaster Studio (OBS) e compartilhamos via Facebook e Whatsapp. A transmissão de vídeos ao vivo precisa ter qualidade para garantir uma boa experiência dos usuários. As características da imagem e som devem ser compreendidas pelo público sem ruídos e a incidência de travamentos durante a transmissão deve ser baixa ou nula. A configuração adequada do software transmissor, em nosso caso o Open Broadcaster Studio, é importante para garantir a qualidade e confiabilidade. A equipe multidisciplinar realizou a configuração da taxa de bits, resolução do codificador ao vivo e a configuração do fps (frames por segundo). A taxa de bits é mensurada em bits por segundos (Kbps), e mede a velocidade com que os dados são enviados (por segundos) para o YouTube, quanto maior a quantidade de bits enviados melhor a qualidade do vídeo. A resolução do vídeo está relacionada ao número de pixel que é possível representar em um monitor, quanto maior a resolução mais bits são necessários enviar. Os fps representam a quantidade de frames, ou fotogramas, exibidos por segundo. Utilizamos na transmissão da aula inaugural de 1280 x 720 pixels de resolução, taxa de bits do vídeo de 2250 e 60 fps.

Foi realizada a rotina de testes com a internet wi-fi e cabeada para verificar qual a taxa de bits adequada para o codificador diante da velocidade disponível de upload na sala de aula utilizada para a transmissão. O YouTube transcodificou o vídeo criando formatos diferentes de saída automaticamente, garantindo a acessibilidade técnica diante dos variados tipos de conexão dos cursistas. Através da página de gerenciamento da transmissão do YouTube, chamada Estúdio de Criação, conseguimos monitorar a qualidade do upload em tempo real. Esta apresentou instabilidade apenas uma vez e não representou interferência significativa nas informações enviadas, que posteriormente ficaram disponíveis para os cursistas no canal Antártica ou Antártida? a fim de serem revisitadas sempre que os cursistas o desejarem.

Os polos, como dissemos anteriormente, nos estados de São Paulo, Rondônia e Minas Gerais, receberam fisicamente os cursistas inscritos daquelas localidades para assistir à transmissão ao vivo. Os estudantes contaram com o auxílio de mediadores pedagógicos, para se conectar com à aula.

(vii) Avaliação: nessa etapa analisamos a qualidade técnica e as fraquezas da transmissão. Realizamos uma análise quantitativa da presença virtual dos cursistas através das suas interações e estatísticas de visualização do YouTube. No total, 257 participantes tiveram acesso à aula e realizaram suas interações com seis tutores através de múltiplas plataformas: chat do YouTube, Facebook e Whatsapp.

(viii) Gestão de Projetos: O gerenciamento da execução da aula incluiu a criação e elaboração dos cronogramas de trabalho e a gestão dos recursos envolvidos. Esta é a etapa que se deve viabilizar toda a infraestrutura necessária para execução e disponibilização da aula.

\footnotetext{
${ }^{1}$ GoPro é uma marca de câmera de ação. Esse tipo de câmera é portátil e leve e permite a captura de imagens e vídeos em ângulos e situações que seriam difíceis com câmeras tradicionais
} 
VII Congresso Brasileiro de Informática na Educação (CBIE 2018)

Anais do XXIV Workshop de Informática na Escola (WIE 2018)

\section{Resultado e Discussão}

A aula inaugural contou com a presença, física ou virtual, de 247 cursistas, distribuídos em Portugal e em treze estados brasileiros conforme mostra o Gráfico 1. Ministrada em língua portuguesa e teve duração de 1 hora 40 minutos e 27 segundos e recebeu 257 comentários pelo chat do YouTube enviados durante a transmissão que tiveram a mediação dos tutores (Tabela 1).

O Brasil representa um percentual significativo nas visualizações e interações, pois a maioria dos cursistas era brasileira, apenas quatro eram portugueses. A exposição da aula foi realizada pela docente que interagiu com os cursistas que estavam presentes na sala de transmissão. Os cursistas que estavam distantes, interagiram on-line com os tutores, por meio do chat do Youtube e do Facebook.

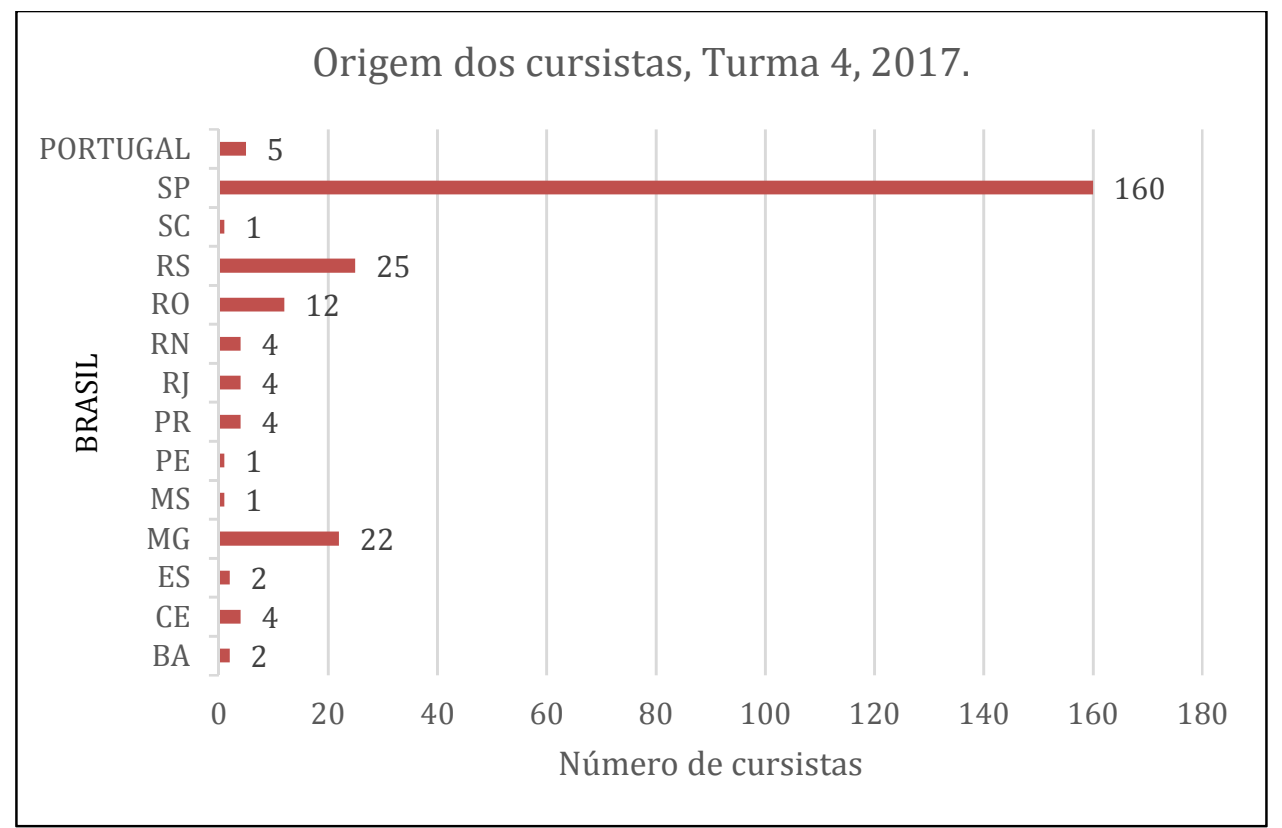

Gráfico 1. Distribuição dos cursistas, Brasil e Portugal, 2017

Tabela 1. Visualização e comentários por país

\begin{tabular}{l|c|c}
\hline PAÍS & VISUALIZAÇÕES & COMENTÁRIOS \\
\hline Brasil & 250 & 245 \\
\hline Coreia do Sul & 1 & 0 \\
\hline Portugal & 4 & 12 \\
\hline Suécia & 2 & 0 \\
\hline Total & 257 & 257 \\
\hline
\end{tabular}

A Tabela 2 apresenta a distribuição da origem do tráfego para a transmissão da aula. A Coréia do Sul e Suécia aparecem na lista devido a conexão dos pesquisadores que faziam parte da equipe multidisciplinar que estavam alocados naqueles países no 
VII Congresso Brasileiro de Informática na Educação (CBIE 2018)

Anais do XXIV Workshop de Informática na Escola (WIE 2018)

momento da aula inaugural. Esses pesquisadores haviam enviado seus vídeos de apresentação de seus papéis na equipe e puderam se conectar à aula. A origem do tráfego representa o caminho e os recursos pelos quais os espectadores utilizaram para chegar até o conteúdo. O tráfego de origem "Direta ou desconhecida" e "Externa" ocorrem quando o usuário acessa o vídeo digitando (ou clicando) a URL diretamente no navegador. $\mathrm{O}$ endereço de URL pode ser enviado por e-mail em uma ação de divulgação. No tráfego pelos "Recursos de navegação", o usuário está inscrito no canal e visualiza a transmissão através das atualizações da página inicial do YouTube, que fornece dados das páginas que ele é seguidor. O sistema de "Páginas do canal" fornece notificações em páginas de outros criadores de conteúdo relacionados ao tema e às palavras-chave contidas no título e descrição do vídeo. As notificações são mensagens oficiais do YouTube e aparecem para os usuários em um tipo de janela flutuante no site ou aplicativo. O tráfego pela "Pesquisa no YouTube" acontece pelos resultados da busca com palavras-chave dentro do site do YouTube. A categoria "Vídeos Sugeridos" indica vídeos para os usuários da plataforma baseado em seu histórico de navegação. As "Anotações e cartões de vídeo", são elementos interativos aplicados na edição que aparecem sobre o vídeo com recomendações para o espectador e possuem links que direcionam para um site ou outro vídeo ao ser clicado. As "Notificações" são exclusivas dos smartphones e tablets e chegam aos usuários inscritos pelo dispositivo ou por e-mail. O tráfego por "Outros recursos do YouTube" não se enquadra em nenhuma das categorias descritas.

Em Portugal, três cursistas e, no Brasil, 87, acessaram a aula através dos "Vídeos sugeridos". Esta categoria indica vídeos para os usuários da plataforma baseado em seu histórico de navegação, um indicador que representa uma proximidade contextual desses cursistas com o tema Antártica. O sistema de sugestão funciona atrelado ao algoritmo de recomendações do YouTube, mesmo existindo uma divulgação do vídeo ao vivo para os cursistas muitos receberam um aviso do site quando se iniciou a transmissão, pelo motivo de já estarem inscritos no canal ou por terem pesquisado e assistido outros vídeos sobre o tema. A origem de navegação externa também foi expressiva, 89, fator que reforça a importância da divulgação, incorporação e adaptação da transmissão para outras plataformas como o Facebook, Moodle e Whatsapp, possibilidade gratuita e nativa para ou vídeos do YouTube.

A página de exibição do YouTube serviu como o principal local de suporte da transmissão ao vivo da aula inaugural. A confiabilidade e usabilidade oferecidas pelo Youtube favorecem o compartilhamento dos vídeos em websites, redes sociais e aplicativos. A disponibilidade do serviço é garantida por se tratar de um sistema executado em uma estrutura robusta de servidores. Também a gratuidade e a popularidade na divulgação dos mais diversos conteúdos, são fatores de escolha importantes para a oferta de aulas. O desafio está na qualidade de conexão de quem assiste e interage e da equipe que envia o streaming de vídeo para os servidores do YouTube. Estudos sobre essas interações ainda precisam ser realizados, a fim de compreendermos os potenciais do Youtube para a condução de aulas síncronas.

Tabela 2 Origem de tráfego para a transmissão ao vivo da aula inaugural

\begin{tabular}{l|l|c}
\hline PAÍS & ORIGEM & VISUALIZAÇÕES \\
\hline Brasil & Direta ou desconhecida & 31 \\
\hline Brasil & Recursos de navegação & 6 \\
\hline Brasil & Páginas do canal & 20 \\
\hline
\end{tabular}


VII Congresso Brasileiro de Informática na Educação (CBIE 2018)

Anais do XXIV Workshop de Informática na Escola (WIE 2018)

\begin{tabular}{l|l|c}
\hline Brasil & Pesquisa do YouTube & 6 \\
\hline Brasil & Vídeos sugeridos & 87 \\
\hline Brasil & Outros recursos do YouTube & 3 \\
\hline Brasil & Externa & 89 \\
\hline Brasil & Anotações e cartões de vídeo & 4 \\
\hline Brasil & Notificações & 1 \\
\hline Coreia do Sul & Externa & 3 \\
\hline Portugal & Vídeos sugeridos & 1 \\
\hline Portugal & Anotações e cartões de vídeo & 1 \\
\hline Suécia & Recursos de navegação & 1 \\
\hline Suécia & Páginas do canal & 257 \\
\hline
\end{tabular}

A escolha do Youtube para a transmissão da aula se deu devido a gratuidade do serviço, mas apresentou muitas limitações, por não oferecer formas de mediação que atendessem às expectativas da docência, conforme registradas em experiências anteriores, realizadas com ferramentas próprias para a condução de aulas síncronas, como por exemplo, o Adobe Connect, uma ferramenta paga que oferece salas de aula virtuais multimídias e multimodais (Dotta, 2014) e que favorece o envolvimento de vários mediadores técnicos e pedagógicos.

\section{Considerações finais}

Neste trabalho, discorremos sobre as demandas técnicas necessárias para conectar professores de múltiplos estados brasileiros e de Portugal para participarem de uma aula presencial a distância em um curso de formação de professores sobre o continente Antártico.

O uso de uma metodologia que considerasse a atuação de uma equipe multidisciplinar para executar o papel do professor coletivo junto a ferramentas de acesso gratuito mostrou-se fundamental para o desenvolvimento e condução da aula promovendo a interação de pessoas de diversas localidades e o rompimento das barreiras impostas para o acesso ao conhecimento científico.

A preparação da aula inaugural partiu de uma abordagem dialógica de aprendizagem, na qual o professor deve abandonar o papel de transmissor de informação e assumir o lugar de agenciador da comunicação e, junto com o aluno, produzir significados. Essa prática foi possível no experimento, devido a atuação de uma equipe multidisciplinar (professor coletivo) e o uso de sistemas de webconferência multimodais e multimídias, cujos recursos ofereceram diferentes possibilidades de interação, como a transmissão de vídeos, o compartilhamento da transmissão para outros ambientes (por exemplo, o Facebook), o chat do Youtube. Apesar da versatilidade da transmissão pelo Youtube, ainda encontramos algumas dificuldades, como, por exemplo, a limitação de interações multimodais. A impossibilidade de se realizar a transmissão de vídeos a partir de diferentes localidades pelo mesmo canal, característica comum em webconferências multimodais, como o Adobe Connect, Hangout etc., é um limitador importante para o uso dessa ferramenta em aulas que buscam intensa interatividade entre docentes, cursistas e tutores. 
VII Congresso Brasileiro de Informática na Educação (CBIE 2018)

Anais do XXIV Workshop de Informática na Escola (WIE 2018)

A facilidade de uso da ferramenta e o auxílio dos mediadores técnicos favoreceram a superação de problemas técnicos e a permanência dos cursistas na aula. A metodologia adotada para o estudo não permite verificar se houve a sensação de pertencimento ao grupo, sugerindo a necessidade de estudos futuros utilizando-se outras metodologias e outros sistemas de webconferência.

\section{Referências}

BELLONI, Maria Luiza. (1999) Educação a distância. Campinas: Autores Associados, 1999. $124 \mathrm{p}$.

BRAGA, Juliana; DOTTA, Silvia; PIMENTEL, Edson e STRANSKY, Beatriz. Desafios para o Desenvolvimento de Objetos de Aprendizagem Reutilizáveis e de Qualidade. Anais do DesafIE!/2012 - Workshop de Desafios da Computação Aplicada à Educação 17 e 18 de Julho de 2012, Curitiba, CEIE/SBC. Disponível em < http://www.brie.org/pub/index.php/desafie/article/view/2779>. Acessos em 11 mar. 2018.

BRAGA, Juliana, DOTTA, Silvia e PIMENTEL, Edson. Objetos de Aprendizagem: Metodologia de Desenvolvimento. Santo André, Editora da UFABC, 2015. (Coleção Intera).

DOTTA, S. (Org.) Aulas Virtuais Síncronas. Santo André, EDUFABC, 2014.

DOTTA, S. et al. Condução de aulas síncronas em sistemas de webconferência multimodal e multimídia. 2012. Anais do XXIII Simpósio Brasileiro de Informática na Educação. Rio de Janeiro, Sociedade Brasileira do Computação. Disponível em: http://www.br-ie.org/pub/index.php/sbie/article/view/1705. Acesso em 11 mar. 2018.

MAIA, Marta Campos e MEIRELLES, Fernando de Souza. Evasão nos Cursos a Distância e sua Relação com as Tecnologias de Informação e Comunicação. Brasília, EnANPAD, 2005. Disponível em: http://www.anpad.org.br/admin/pdf/enanpad2005adic-2311.pdf. Acesso em: 09/06/2018.

MOORE. Michael G.; KEARSLEY, Greg. Educação a distância: sistemas de aprendizagem on-line. São Paulo: Cengage Learning, 2013.

SILVA, Marco. Sala de aula interativa. Rio de Janeiro, Quarter, 2000. 232 p.

TORI, Romero. Educação sem distância: As tecnologias interativas na redução de distâncias em ensino e aprendizagem. 2. ed. São Paulo: Artesanato Educacional, 2017.

YOUTUBE. Google. Origens do tráfego para visualizações. Disponível em: $<$ https://support.google.com/youtube/answer/1714921?hl=pt-BR>. Acesso em: 06 maio 2018. 